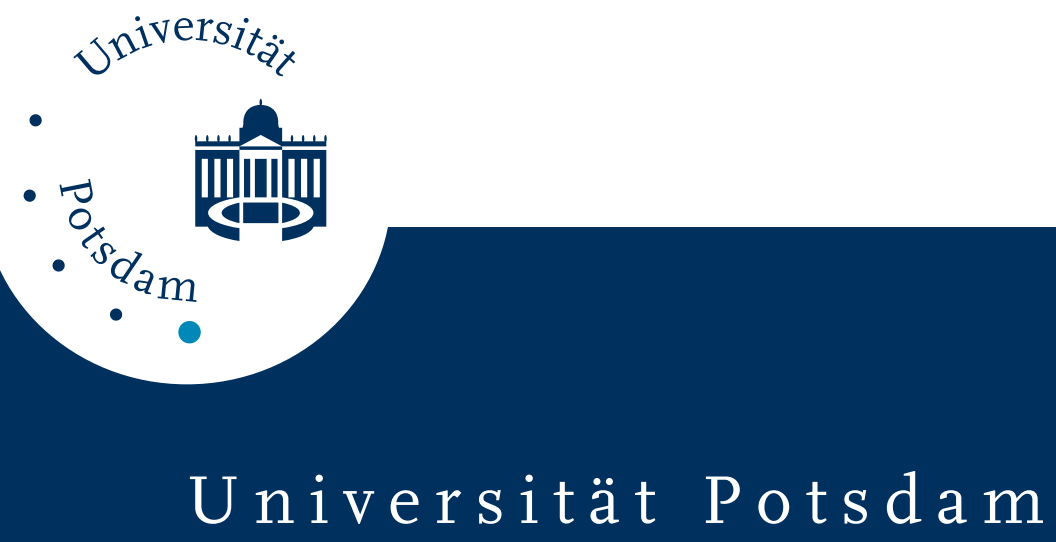

Cochin, D.; Hendlinger, P.; Laschewsky, André

\title{
Polysoaps with fluorocarbon hydrophobic chains
}

first published in:

Colloid \& Polymer Science, 273 (1995), 12, S. 1138-1143, ISSN 0303-402X, DOI 10.1007/BF00653081

Postprint published at the Institutional Repository of Potsdam University:

In: Postprints der Universität Potsdam

Mathematisch-Naturwissenschaftliche Reihe ; 85

http://opus.kobv.de/ubp/volltexte/2008/1734/

http://nbn-resolving.de/urn:nbn:de:kobv:517-opus-17347

Postprints der Universität Potsdam

Mathematisch-Naturwissenschaftliche Reihe ; 85 
D. Cochin

P. Hendlinger

A. Laschewsky
Polysoaps with fluorocarbon hydrophobic chains
Received: 1 June 1995

Accepted: 3 July 1995

D. Cochin $\cdot$ P. Hendlinger

Prof. Dr. A. Laschewsky (区)

Université Catholique de Louvain

Dépt. de Chimie

Place L. Pasteur

1348 Louvain-la-Neuve, Belgium
Abstract A series of amphiphilic copolymers is prepared by copolymerization of choline methacrylate with 1,1,2,2-tetrahydroperfluorooctyl methacrylate in varying amounts. The copolymers bearing fluorocarbon chains are studied concerning their effects on viscosity, solubilization and surface activity in aqueous solution, exhibiting a general behavior characteristic for polysoaps. The results are compared with the ones obtained for an analogous series of amphiphilic copolymers bearing hydrocarbon chains.

Key words Amphiphilic polymers fluorocarbon polymers - associating polymers - polysoaps

\section{Introduction}

By virtue of their strong tendency to self-organize in aqueous media and of their industrial importance, watersoluble amphiphilic polymers attract increasing attention. "Polysoaps" [1-3] represent a particular class within such polymers which is characterized by many analogies to micelle-forming surfactants.

Though the hydrophobic parts of amphiphiles are generally made from hydrocarbon chains, a number of alternatives exists, including, e.g., siloxanes, oligo (propylene oxides) or fluorocarbons. Such alternative hydrophobic groups have been increasingly explored in low molecular weight surfactants due to their different qualities - such as flexibility, surface energy, hydrophobicity and oleophobicity [4] - but their use in amphiphilic polymers is exceptional. In particular, the use of fluorocarbon hydrophobic chains in polymers has so far been very limited. The few studies have been restricted basically to water-soluble polymers which are weakly substituted with fluorocarbon chains to provide efficient thickeners [5-10], or to block copolymers [11-15] or oligomers $[16,17]$ respectively. Examples for water-soluble polymers which are heavily substituted with fluorocarbon chains, as needed for poly- soaps to enable intramolecular aggregation, are virtually missing.

Here, the synthesis and investigation of fluorocarbon

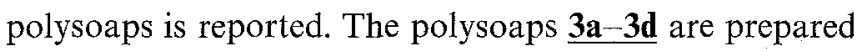
by random copolymerization of the hydrophilic monomer choline methacrylate 1 with the 1,1,2,2-tetrahydro-perfluorooctyl methacrylate $\underline{\mathbf{2}}$ in varying amounts (Fig. 1). These fluorocarbon polysoaps are of the so-called "headtype" geometry $[3,18]$, having a chemical structure similar

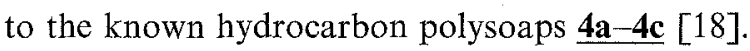

\section{Experimental Part}

Monomer 1 was a gift from B. Schlarb, monomer 2 was a gift from Hoechst Co. (Germany). Monomers $\underline{1}$ and $\mathbf{2}$ are copolymerized at $60^{\circ} \mathrm{C}$ for $12 \mathrm{~h}$, reacting $0.200 \mathrm{~g}$ of 2 dissolved in $5 \mathrm{ml}$ of ethanol with the calculated amount of 1 and $1 \mathrm{~mol} \%$ of azobis (isobutyronitrile) AIBN as in-

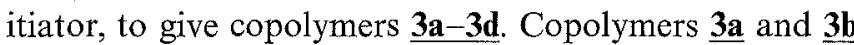
precipitate during polymerization; they are separated by filtration, extracted with ethanol, dissolved in water, and precipitated in acetone. Copolymers $\underline{3 \mathbf{c}}$ and $\underline{\mathbf{3 d}}$ are repeatedly precipitated in acetone from ethanol solutions. 
$\mathrm{CH}_{2}=\stackrel{\stackrel{\mathrm{I}}{\mathrm{C}}-\underset{\mathrm{H}}{\mathrm{C}}-\mathrm{C}}{\mathrm{C}}-\mathrm{O}-\mathrm{CH}_{2}-\mathrm{CH}_{2}-\mathrm{N}^{+}\left(\mathrm{CH}_{3}\right)_{3} \mathrm{Br}^{-}$
$\mathrm{CH}_{2}=\stackrel{\substack{\mathrm{C} \\ \mathrm{C}}}{\underset{0}{\mathrm{C}}-\mathrm{C}}-\mathrm{O} \cdot \mathrm{CH}_{2}-\mathrm{CH}_{2}-\left(\mathrm{CF}_{2}\right)_{5}-\mathrm{CF}_{3}$

$\underline{2}$

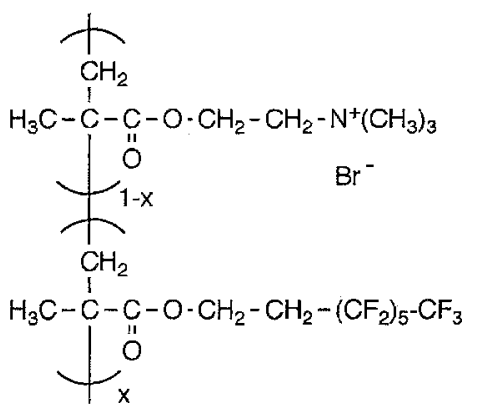

3a: $x=0.15$

3b: $x=0.21$

3c: $x=0.34$

3c: $x=0.53$

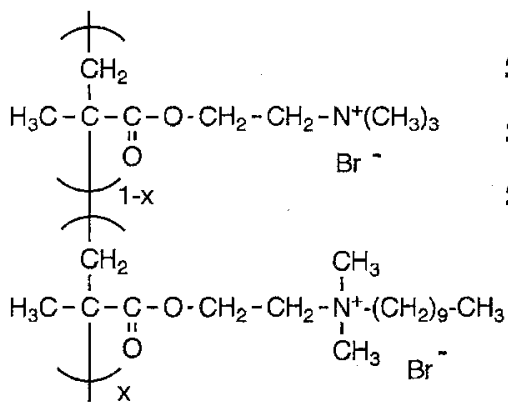

4a: $x=0.10$

4b: $x=0.17$

4c: $x=0.40$

Fig. 1 Monomers and copolymers used

The synthesis of copolymers $\mathbf{4 a - 4 c}$ was described previously [18]. The azodye 4-(4-butylphenylazo)-N,Ndiethylaniline $\underline{\mathbf{5}}$ was synthesized by standard coupling reaction of 4-butylaniline and N,N-diethylaniline [19].

Water used for all experiments was purified by a Milli$Q$ water purification system (resistance $18 \mathrm{M} \Omega$ ).

NMR-spectra were recorded by a Gemini $300 \mathrm{MHz}$ spectrometer. $\mathrm{CFCl}_{3}$ was used as internal standard for ${ }^{19} \mathrm{~F}$-spectra. IR-spectra were recorded by a Nicolet type 205 FT-IR spectrometer. Elemental analysis was done by the University College of London. Viscometry was performed by a semi-automatic Ubbelohde capillary viscometer (Schott) in water at $25^{\circ} \mathrm{C}$. Solubilization experiments were done by shaking $4 \mathrm{wt} \%$ aqueous solutions of the polymers with an excess of dye for 4 weeks at $18^{\circ} \mathrm{C}$, followed by centrifugation and filtration to give clear, colored solutions which are measured by UV/Vis spectroscopy (SLM AMINCO DW-2000 spectrometer).

Thermogravimetry was performed on a thermogravimetric analyzer TGA-500 SETARAM, with a heating rate of $10^{\circ} \mathrm{C} / \mathrm{min}$ in nitrogen atmosphere. Differential scanning calorimetry d.s.c was performed with a PerkinElmer DSC7, applying heating and cooling rates of $20^{\circ} \mathrm{C} / \mathrm{min}$. X-ray scattering experiments were done with a diffractometer Siemens D-500 Siemens, using the Nifiltered $\mathrm{Cu}-\mathrm{K}_{\alpha}$-line $(\lambda=0.1541 \mathrm{~nm})$.

\section{Results and Discussion}

Synthesis and general properties of the copolymers

Copolymers $3 \mathbf{3 a - 3 d}$ are prepared by free radical copolymerization of the cationic methacrylate 1 with the
Table 1 Composition of the monomer feeds of 1 and $\mathbf{2}$, and of the resulting copolymers $\mathbf{3 a - 3 \mathbf { d }}$ as determined by elemental analysis of $\mathrm{N}$ and $\mathrm{Br}$

\begin{tabular}{lllll}
\hline Copolymer & $\begin{array}{l}\text { Molar fraction of } \\
\text { monomer 2 } \\
\text { in the feed }\end{array}$ & $\begin{array}{l}\text { Yield } \\
(\%)\end{array}$ & $\begin{array}{l}\text { Molar fraction of } \\
\text { monomer 2 } \\
\text { in the copolymer }\end{array}$ \\
\cline { 3 - 5 } & & $\mathrm{X}_{2}(\mathrm{~N})$ & $\mathrm{X}_{2}(\mathrm{Br})$ \\
\hline$\underline{\mathbf{3 a}}$ & 0.091 & 80 & 0.15 & 0.17 \\
$\underline{\underline{\mathbf{3 b}}}$ & 0.17 & 48 & 0.21 & 0.20 \\
$\underline{\underline{\mathbf{3 d}}}$ & 0.33 & 34 & 0.34 & 0.33 \\
\hline
\end{tabular}

fluorocarbon methacrylate $\mathbf{2}$ in solution. Table 1 lists the composition of the respective monomer feeds and of the resulting copolymers. As both compositions are rather close even at moderate conversions with a slight preference for monomer 2, we can assume a copolymerization behavior not too different from ideal statistical copolymerization of both methacrylates.

Copolymers $\underline{\mathbf{3 a}-\mathbf{3 d}}$ were characterized by ${ }^{1} \mathrm{H}-\mathrm{NMR}$, ${ }^{19} \mathrm{~F}-\mathrm{NMR}$ and FT-IR spectroscopy, and by elemental analysis, to give satisfactory results (cf. Table 1, Fig. 2). Thermogravimetric analysis indicated decomposition above $190^{\circ} \mathrm{C}$; no thermal transition could be observed by d.s.c.. Unlike the homopolymers, $x$-ray powder diffractograms of copolymers $\mathbf{3 b} \mathbf{3} \mathbf{d}$ exhibit one small angle signal at $2 \theta=2^{\circ}$ in addition to the halo around $2 \theta=17^{\circ}$. This behavior is similar to the one of the hydrocarbon analog $\underline{\mathbf{4 c}}$ [18]. The small-angle peak was attributed to a lamellar superstructure due to microphase separation of the ionic and the hydrophobic fragments of the copolymers. That 
Fig. $2{ }^{1} \mathrm{H}-\mathrm{NMR}(300 \mathrm{MHz})$ and ${ }^{19} \mathrm{~F}-\mathrm{NMR}$ (188 MHz) spectra of copolymer $3 \mathrm{c}$ at room temperature (x: $\bar{\equiv} 0.34$ ). from top to bottom: ${ }^{1} \mathrm{H}-\mathrm{NMR}$ in $\mathrm{D}_{2} \mathrm{O},{ }^{1} \mathrm{H}-\mathrm{NMR}$ in $\mathrm{CDCl}_{3} / \mathrm{CD}_{3} \mathrm{OD},{ }^{19} \mathrm{~F}-\mathrm{NMR}$, in $\mathrm{D}_{2} \mathrm{O},{ }^{19} \mathrm{~F}-\mathrm{NMR}$ in $\mathrm{CDCl}_{3} / \mathrm{CD}_{3} \mathrm{OD} 1 \mathrm{v} / 1 \mathrm{v},{ }^{19} \mathrm{~F}$ $\mathrm{NMR}$ in $\mathrm{CD}_{3} \mathrm{OD}$
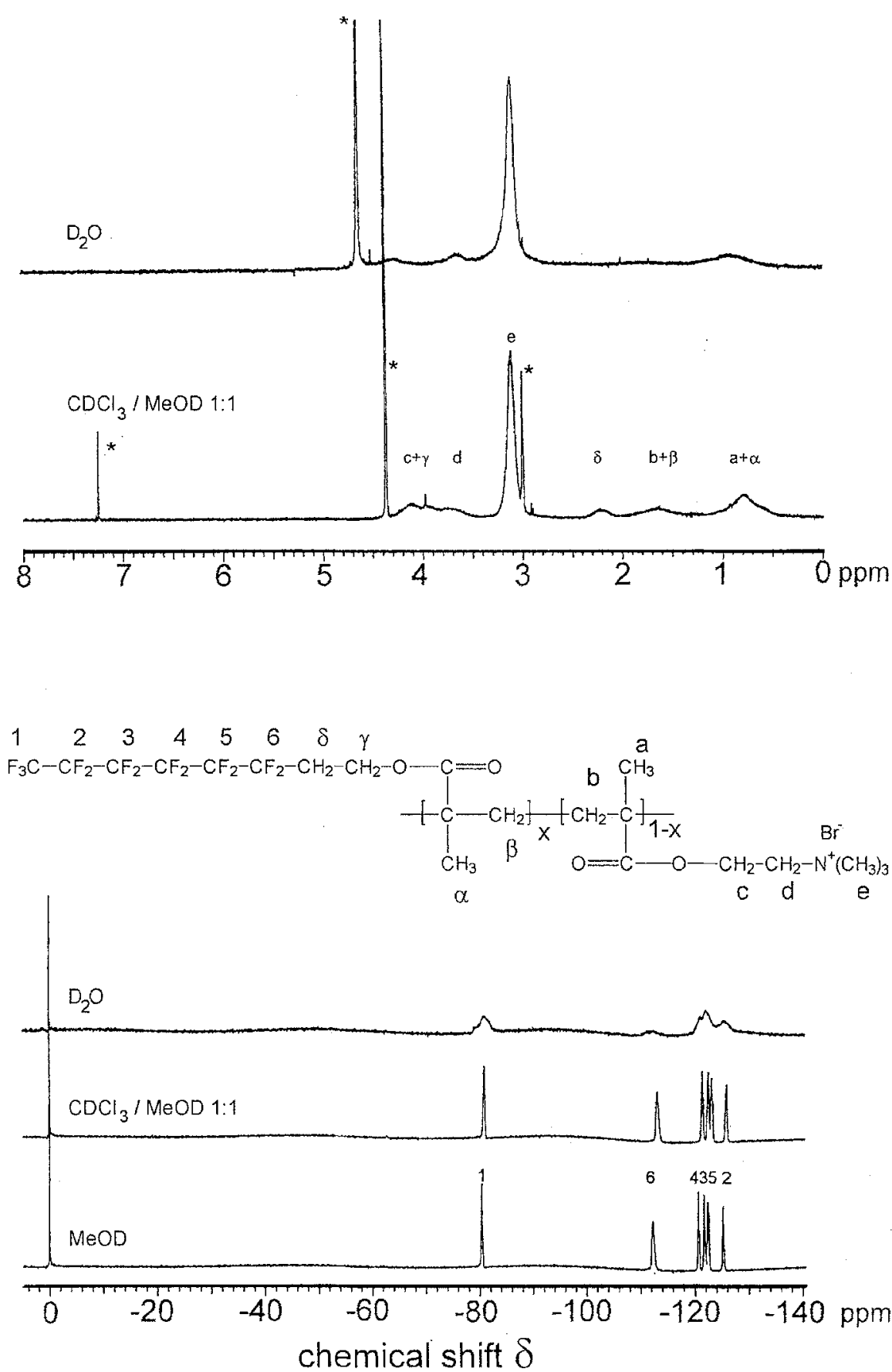

superstructure formation in the series $\mathbf{3 a - 3 d}$ occurs at lower hydrophobe contents than in the series of their hydrocarbon analogs $\mathbf{4 a - 4 c}$, can be explained by the stronger hydrophobicity of the fluorocarbon chains.

Attempts to characterize the degree of polymerization

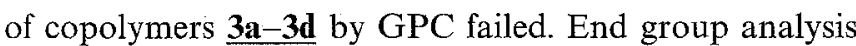
by NMR and FT-IR spectroscopy enabled however an estimation of the lower limit: as nitrile end-groups could

not be detected, the degree of polymerization of the copolymers must exceed 20 .

Copolymers $\underline{3 \mathbf{a}-\mathbf{3 d}}$ are insoluble in acetone, dioxane and $\mathrm{CHCl}_{3}$. They are soluble in methanol and $1 \mathrm{v} / 1 \mathrm{v}$ mix-

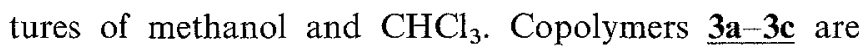
water-soluble, whereas $\underline{\mathbf{3 d}}$ swells only. This observation agrees well with previous findings on the limits of water solubility of copolymers of the "head type" geometry 
hydrophobized by hydrocarbon chains which were explained by a spacer model $[3,18,20]$.

Characteristically, ${ }^{1} \mathrm{H}-\mathrm{NMR}$ and ${ }^{19} \mathrm{~F}-\mathrm{NMR}$ spectra of copolymers $\underline{\mathbf{3}-\mathbf{3} \mathbf{c}}$ have the usual polymeric appearance in organic solvents such as $\mathrm{CDCl}_{3} / \mathrm{CD}_{3} \mathrm{OD}$ mixtures or $\mathrm{CD}_{3} \mathrm{OD}$, whereas the signals of the hydrophobic fragments are strongly broadened in $\mathrm{D}_{2} \mathrm{O}$, or are even missing (Fig. 2). The broadening effect is particularly visible in the ${ }^{19} \mathrm{~F}$-spectra. This behavior points to a reduced mobility due to hydrophobic aggregation in aqueous media, as observed for many other hydrophobized water-soluble polymers [21-24]. But noteworthy despite their strong broadening, fluorine signals are still observed, in contrast to reports on polyacrylamides with low contents of fluorocarbon groups [25].

\section{Polysoap behavior}

Within the water-soluble amphiphilic polymers, polysoaps are characterized by two prominent properties: i) relatively low reduced viscosities in water, compared to their analogs lacking hydrophobic groups, and ii) the ability to solubilize hydrophobic compounds in water. Both properties are attributed to the intramolecular formation of hydrophobic domains, often referred to as "polymeric micelles", in analogy with micelles formed from standard surfactants. For standard surfactants, surface activity has to be added as key property, whereas polysoaps may or may not be surface active, depending on their detailed structure [3].

Hence, these three key properties, reduced viscosity, solubilization capacity and surface activity were investigated for the fluorocarbon copolymers $\mathbf{3 a - 3 \mathbf { c }}$ (Figs. 3-5), and compared with the behavior of the known hydrocar-

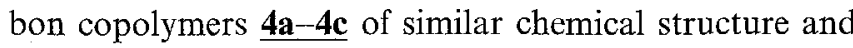
hydrophobe content.

\section{Viscosimetry}

The reduced viscosities $\eta_{\mathrm{red}}=\eta_{\mathrm{spec}} / \mathrm{c}$ of aqueous solutions of $\mathbf{3 a - 3 c}$ are plotted in Fig. 3 as function of the copolymer concentration. For comparison, the results for the homopolymer of choline methacrylate poly-1 and for the hydrocarbon analogs $\underline{\mathbf{s}}$ and $\underline{\mathbf{4}}$ are added.

Characteristically, all polymers exhibit polyelectrolyte behavior: in the low concentration range, the values of $\eta_{\text {red }}$ increase with decreasing concentration. Still, it is evident that the hydrophobized copolymer series $\underline{\mathbf{3 a}-\mathbf{3 c} \text { and }}$ 4b-4c exhibit substantially lower $\eta_{\text {red }}$ values than poly-1 There is no indication of thickening effects as observed fo watersoluble copolymers with a very small fluorocarbon

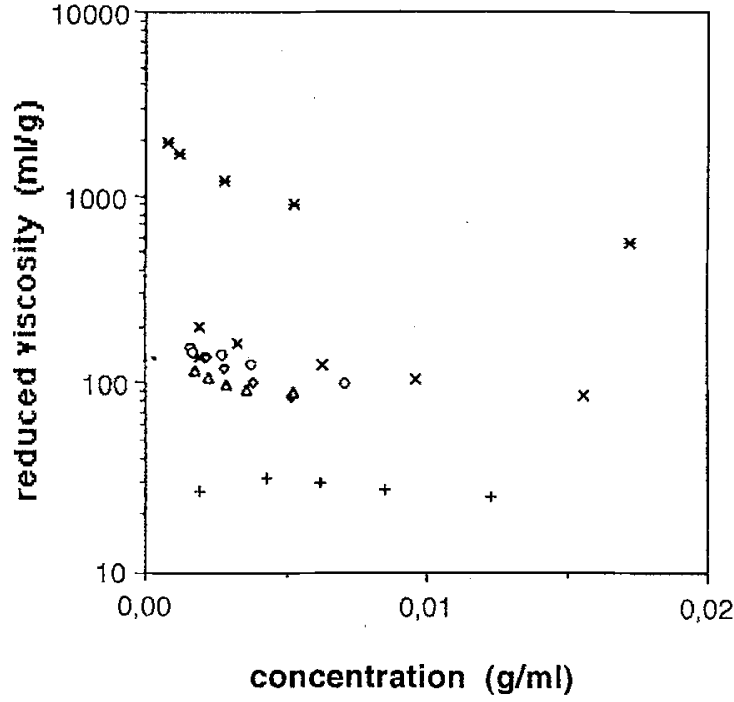

Fig. 3 Reduced viscosity $\eta_{\text {red }}$ of aqueous polymer solutions at $25^{\circ} \mathrm{C}$, as function of the concentration for poly-1 $(*)$, copolymers $\underline{\mathbf{3 a}}(\circ)$, $\underline{\mathbf{3 b}}(\Delta)$ and $\underline{3 \mathbf{c}}(\diamond)$, copolymers $\underline{\mathbf{4 b}}(\times), \underline{\mathbf{4 c}(+)}$

hydrophobe content $[5-11,25]$. Though effects due to strongly differing degrees of polymerization cannot be rigorously excluded as the molar masses are unknown, they are highly improbable as the polymerization conditions for the polymers were virtually identical. Therefore, the behavior of the fluorinated copolymers is qualitatively in agreement with the one of classical polysoaps which is attributed to an intramolecular hydrophobic aggregation [26-30]. Noteworthy is that polysoap behavior is already observed for copolymer $\mathbf{3 a}$ which contains $10 \mathrm{~mol} \%$ of 1,1,2,2-tetrahydro-perfluorooctyl chains, whereas much higher contents of octyl chains are usually needed [30,31], thus demonstrating once more the higher hydrophobicity of fluorocarbon chains.

A more detailed look at the viscometry data shows that the reduced viscosity of the hydrocarbon copolymers strongly decreases with increasing hydrophobic content from $\underline{\mathbf{4 b}}$ to $\underline{\mathbf{4}}$, as reported for other polysoaps in the literature. This behavior is attributed to an increasing intramolecular hydrophobic aggregation. In contrast, all three fluorocarbon copolymers $\underline{\mathbf{3} a-\mathbf{3} c}$ exhibit comparable reduced viscosities. Unfortunately, it cannot be decided whether this is a characteristic feature for such fluorinated polysoaps, or whether differences in the molecular weights are responsible.

\section{Solubilization}

The ability of copolymers $\underline{3 a-3 c}$ to solubilize hydrophobic compounds in water was studied for the azo dye $\underline{\mathbf{5}}$. This 


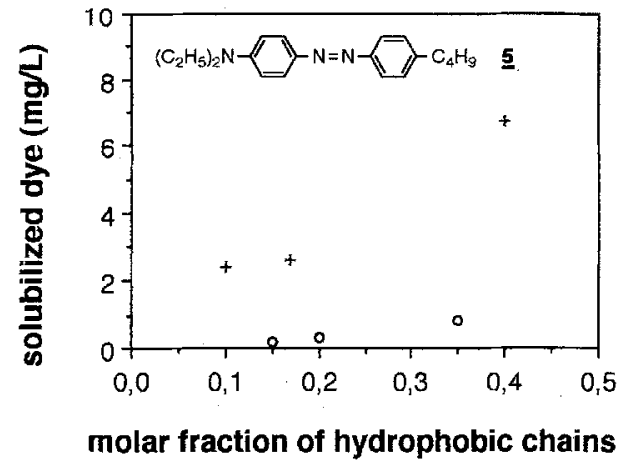

Fig. 4 Solubilization of azo dye $\underline{\mathbf{5}}$ in water by copolymers $\underline{\mathbf{3 a}-\mathbf{3} \mathbf{c}}$ (o) and by copolymers $\mathbf{4 a}-\mathbf{4 c}(+$, data taken from ref. [19]), (polymer concentration: $=4 \mathrm{~g} / \mathrm{L})$

compound was used previously in studies of the analogous hydrocarbon copolymers $\underline{\mathbf{4 a}-\mathbf{4} \mathbf{c}}[19,32]$. The results are shown in Fig. 4.

The figure basically demonstrates that the fluorocarbon copolymers are indeed capable of solubilizing hydrophobic compounds. Solubilization capacities increase with increasing hydrophobe content. However, compared to hydrocarbon analogs $\underline{\mathbf{4 a}-\mathbf{4 c}}$ the capacities are much smaller [19]. Realizing the reduced length of the hydrophobic chains (octyl versus decyl), and keeping in mind that fluorocarbon chains are both hydrophobic and oleophobic, i.e., per se not particularly suited to accommodate hydrocarbon solubilizates, this finding is not surprising. Nevertheless, the observed solubilization capacities, albeit small, corrobate the presence of hydrophobic microdomains for $\mathbf{3 a - 3 \mathbf { c }}$.

\section{Surface tension measurements}

Surface tension measurements of copolymers $\mathbf{3 a - 3}$ c are shown in Fig. 5. The copolymers show a notable surface activity, in particular at elevated concentrations, but no break point pointing to a critical micelle concentration (CMC) can be identified.

This general behavior agrees well with the one reported for other polysoaps of the "head type" geometry

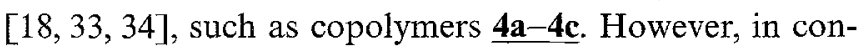
trast to such hydrocarbon polysoaps, the surface tension of aqueous solutions is not reduced with increasing content of hydrophobic chains in the copolymers: on the contrary, the surface tension is most reduced for copolymer $\underline{\mathbf{3 a}}$, increasing for a given concentration in the

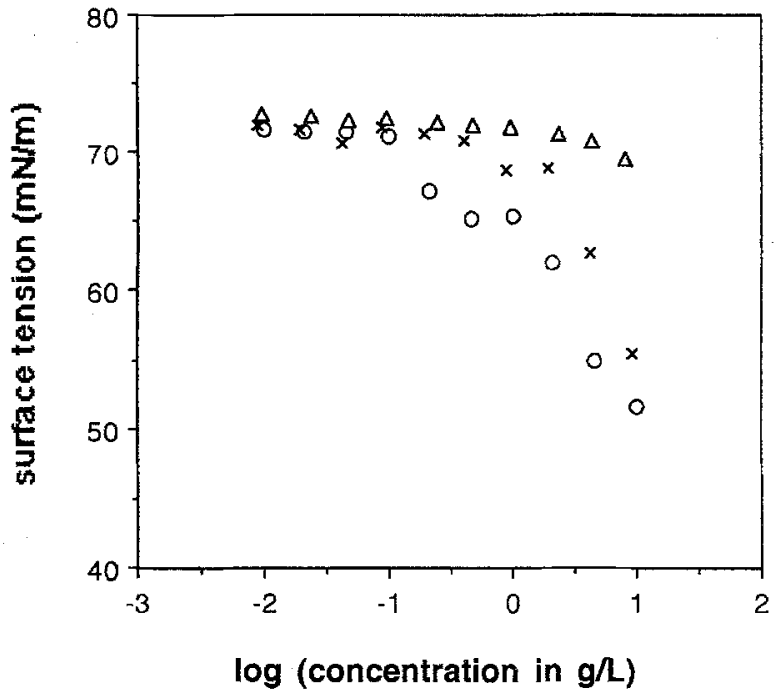

Fig. 5 Surface activity of fluorinated polysoaps: $O=\underline{\mathbf{3 a}}, \mathrm{x}=\underline{\mathbf{3} \mathbf{b}}$ and $\Delta=\underline{\mathbf{3 c}}$

series $3 \mathbf{a}<\mathbf{3 b}<\mathbf{3} \mathbf{c}$, i.e., with increasing content of fluorocarbon chains.

There is no obvious explanation for this unexpected result, though it is not unparalleled in the literature $[35,36]$. It clearly requires further investigation. Possibly, the strong hydrophobic effect of fluorocarbons could cause the superposition of intramolecular and intermolecular hydrophobic aggregation whose relative contributions would change with the fluorocarbon content in the copolymers. This putative explanation might also play a role in the weak dependence of the reduced viscosities of $\underline{3 a-3 c}$ with increasing fluorocarbon content (cf. Fig. 3).

\section{Conclusions}

The fluorocarbon copolymers studied exhibit hydrophobic aggregation in water with characteristic behavior of polysoaps, concerning effects on viscosity, solubilization and surface activity. Nevertheless, the detailed properties show some marked differences compared to the ones of hydrocarbon analogs. Although the reasons for these differences remain to be clarified, the present results demonstrate the usefulness of replacing hydrocarbon chains by fluorocarbon ones to create polysoaps with a modified spectrum of properties.

Acknowledgement The work was supported by the EC program Human Capital and Mobility (grant CHRX-CT-0273). 


\section{References}

1. Strauss UP (1989) In: Glass JE (ed) Polymers in Aqueous Media. Adv Chemistry Series 223, Am Chem Soc, Washington DC, pp 317-324

2. Bekturov EA, Bakauova ZKh (1986) Synthetic Water-Soluble Polymers in Solution. Hütig \& Wepf, Basel, pp 178-199

3. Laschewsky A (1995) Adv Polym Sci $124: 1$

4. Mukerjee $P(1994)$ Colloid Surfaces 84:1

5. Zhang YX, Da AH, Butler GB, HogenEsch TE (1992) J Polym Sci Polym Chem Ed A30:1383

6. Hwang FS, Hogen-Esch TE (1993) Macromolecules 26:3156

7. Watterson AC, Haralabakopoulos A Salamone JC (1993) Polym Prepr Am Chem Soc Div Polym Chem 34(1):610

8. Kästner $U$, Hoffmann $H$, Dönges $R$, Ehrler R (1994) Colloids Surfaces A82:279

9. Hwang FS, Hogen-Esch TE (1995) Macromolecules 28:3328

10. Hogen-Esch TE, Amis A (1995) Trends Polym Sci 3:98

11. Miyamoto M, Aoi K, Saegusa T (1989) Macromolecules 22:3540

12. Selve C, Achilefu S (1990) J Chem Soc Chem Commun 911
13. Boyer B, Lamaty G, Moussamou-Missima JM, Pavia AA, Pucci B, Roque JP (1991) Eur Polym J 27:1359

14. Sawada $\mathrm{H}$, Gong YF, Minoshima $\mathrm{Y}$, Matsumoto T, Nakayama M, Kosugi $M$, Migita T (1992) J Chem Soc Chem Commun 537

15. Meissner E, Myszkowski J, Szymanowski J, Barhoum R (1993) J Chem Tech Biotechnol 57:49

16. Pavia AA, Pucci B, Riess JG, Zarif L (1992) Makromol Chem 193:2505

17. Szajdzinska-Pietek E, Schlick S, Plonka A (1994) Langmuir 10:1101

18. Köberle $P$, Laschewsky $A$, van den Boogaard D (1992) Polymer 33:4029

19. Anton P, Laschewsky A (1994) Colloid Polym Sci 272:1118

20. Anton P, Laschewsky A (1993) Makromol Chem 194:601-624

21. Laschewsky A, Zerbe I (1991) Polymer 32:2081

22. Shoda SI, Masuda E, Furukawa M Kobayashi S (1992) J Polym Sci Polym Chem Ed A30:1489

23. Morishima Y, Tsuji M, Seki M, Kamachi M (1993) Macromolecules 26:3299
24. Morishima $Y$, Nomura S, Seki $M$ Kamachi M (1995) Macromolecules 28:2874

25. Yassini M, Hogen-Esch TE (1994) Polym Prepr Am Chem Soc Polym Chem Div 35(1) 478

26. Strauss UP, Gershfeld NL, Crook EH (1956) J Phys Chem 60:577

27. Woermann D, Wall FT (1960) J Phys Chem 64:581

28. McCormick CL, Chang Y (1994) Macromolecules $27: 2151$

29. Branham KD, Davis DL, Middleton JC McCormick CL (1994) Polymer 35:4429

30. Deboudt K, Delporte M, Loucheux C (1995) Macromol Chem Phys 196:303

31. Inoue H (1964) Kolloid Z u Z Polymere 195:102

32. Anton $\mathrm{P}$, Köberle $\mathrm{P}$, Laschewsky A (1993) Makromol Chem 194:1-27

33. Rios HE, Rojas JS, Gamboa IC, Barraza RG (1993) J Colloid Interface Sci $156: 388$

34. Rios HE, Aravena MH, Barraza RG (1994) J Colloid Interface Sci 165:259

35. Weinert RJ, Piirma I (1989) J Appl Polym Sci 38:1295

36. Menger FM, Littau CA (1993) J Am Chem Soc 115:10083 